\title{
ANALISIS MANAJEMEN RISIKO BERBASIS ISO 31000:2009 PADA MODEL OPTIMASI PENGEMBANGAN DESTINASI WISATA SPIRITUAL
}

\section{ANALYSIS OF ISO 31000:2009 OF RISK MANAGEMENT IN OPTIMIZATION OF A MODEL FOR DEVELOPMENT OF SPIRITUAL TOURISM DESTINATIONS}

\author{
Y Kusumawardhani1a \\ ${ }^{1}$ Program Studi Usaha Perjalanan Wisata, Sekolah Tinggi Pariwisata Bogor \\ aKorespondensi: Iskandar Zulkamain E-mail: Iskandarzul1011@gmail.com \\ (Diterima: 22-12-2018; Ditelaah: 24-12-2018; Disetujui: 06-01-2019)
}

\begin{abstract}
The tourism sector in Indonesia has a significant contribution to the country's economy. This is evidenced by the increasing number of foreign tourists visiting Indonesia from year to year. Tourism development needs to be done in order to attract more tourists. The development of tourism currently trending is spiritual tourism. Spiritual tourism is considered to respect local culture, love nature and the environment, and the tourists are also taught to get to know the local culture. Pura Parahyangan Agung Jagatkarta has a natural beauty because it is located under the foot of Mount Salak. This place has the potential to become a spiritual tourism object because this site is still used as a place of worship by Hindus today. In developing spiritual tourism destinations, there are many risks that will be faced by the developer. This study aims to find out what risks can possibly arise during the process of implementation of the model optimization and then formulate ISO 31000: 2009 of risk management. The results of this study illustrate that ISO 31000: 2009 based on risk management has been, designed to optimize models which can help maximize the performance of the optimization model itself in the implementation process i.e. by minimizing the risks that occur. Existing constraints or risks can be solved quickly by empowering the community and using effective local technology in effective and efficient way.
\end{abstract}

Keywords: Risk management, spiritual tourism

\begin{abstract}
ABSTRAK
Sektor pariwisata di Indonesia memiliki kontribusi yang besar pada perekonomian negara. Hal ini dibuktikan dengan jumlah kunjungan wisatawan asing ke Indonesia dari tahun ke tahun semakin meningkat. Pengembangan pariwisata perlu dilakukan dalam rangka menarik wisatawan lebih banyak lagi. Pengembangan pariwisata yang saat ini sedang tren salah satunya adalah wisata spiritual. Wisata spiritual dinilai menghargai budaya lokal, mencintai alam dan lingkungan, serta wisatawan yang datang juga diajarkan untuk mengenal budaya lokal. Pura Parahyangan Agung Jagatkartta memiliki keindahan alam karena letaknya dibawah kaki Gunung Salak. Tempat ini berpotensi untuk dijadikan suatu objek wisata spiritual, karena Pura ini masih dijadikan tempat beribadah oleh umat Hindu hingga saat ini. Pada pengembangan destinasi wisata spiritual ditemukan banyak risiko-risiko yang akan dihadapi oleh pihak pengembang. Penelitian ini bertujuan menemukan risiko-risiko apa saja yang timbul pada proses implementasi model optimasi kemudian merumuskan manajemen risiko berbasis ISO 31000:2009. Hasil penelitian ini memberikan gambaran bahwa manajemen risiko berbasis ISO 31000:2009 yang telah dirancang untuk model optimasi dapat membantu memaksimalkan kinerja model optimasi itu sendiri pada proses implementasinya, yaitu dengan meminimalkan risiko-risiko yang terjadi. Kendala atau risiko yang ada dapat ditanggulangi secara cepat dengan cara pemberdayaan masyarakat dan penggunaan teknologi lokal yang tepat guna secara efektif dan efisien.
\end{abstract}


Kata kunci : Menejemen resiko, wisata spiritual

Kusumawardhani, Y. (2019). Analisis Manajemen Risiko Berbasis ISO 31000:2009 Pada Model Optimasi Pengembangan Destinasi Wisata Spiritual. Jurnal Sosial Humaniora, 10(1), 28-39.

\section{PENDAHULUAN}

Sektor pariwisata menyumbang sekitar $4 \%$ dari total perekonomian Indonesia. Angka 4\% diperoleh karena wisatawan asing rata-rata akan menghabiskan sekitar 1.200 dollar per kunjungan. Fenomena seperti ini dapat dijadikan sebagai sumber pendapatan devisa dan menekan angka pengangguran di Indonesia. Berdasarkan (BPS 2016), berikut adalah data wisatawan asing per Januari 2016.

Tabel 1. Data Kunjungan Wisatawan Asing dari Tahun 2007 - 2015

\begin{tabular}{|lc|c|c|c|c|c|c|c|c|c|}
\hline & & $\mathbf{2 0 0 7}$ & $\mathbf{2 0 0 8}$ & $\mathbf{2 0 0 9}$ & $\mathbf{2 0 1 0}$ & $\mathbf{2 0 1 1}$ & $\mathbf{2 0 1 2}$ & $\mathbf{2 0 1 3}$ & $\mathbf{2 0 1 4}$ & $\mathbf{2 0 1 5}$ \\
\hline $\begin{array}{l}\text { Wisatawan } \\
\text { (Jutaan) }\end{array}$ & Asing & 5.51 & 6.23 & 6.32 & 7.00 & 7.65 & 8.04 & 8.80 & 9.44 & 9.73 \\
\hline
\end{tabular}

Table 2. Data Kunjungan Wisatawan dari Tahun 2014 - 2016

\begin{tabular}{|l|c|c|c|c|}
\hline \multicolumn{1}{|c|}{ Bulan } & $\begin{array}{c}\text { Kunjungan } \\
\text { Wisatawan } \\
\mathbf{2 0 1 3}\end{array}$ & $\begin{array}{c}\text { Kunjungan } \\
\text { Wisatawan 2014 }\end{array}$ & $\begin{array}{c}\text { Kunjungan } \\
\text { Wisatawan } \\
\mathbf{2 0 1 5}\end{array}$ & $\begin{array}{c}\text { Kunjungan } \\
\text { Wisatawan } \\
\mathbf{2 0 1 6}\end{array}$ \\
\hline Januari & 614,328 & 753,079 & 723,039 & 814,303 \\
\hline Februari & 678,415 & 702,666 & 786,653 & 888,309 \\
\hline Maret & 725,316 & 765,607 & 789,596 & 915,019 \\
\hline April & 646,117 & 726,332 & 749,882 & 901,095 \\
\hline Mei & 700,708 & 752,363 & 793,499 & 915,206 \\
\hline Juni & 789,594 & 851,475 & 815,148 & 857,651 \\
\hline Juli & 717,784 & 777,210 & 814,233 & $1,032,741$ \\
\hline Agustus & 771,009 & 826,821 & 850,542 & $1,031,986$ \\
\hline September & 770,878 & 791,296 & 869,179 & $1,006,653$ \\
\hline Oktober & 719,900 & 808,767 & 825,818 & $1,040,651$ \\
\hline November & 807,422 & 764,461 & 777,976 & \\
\hline Desember & 766,966 & 915,334 & 913,828 & \\
\hline Total & $\mathbf{8 , 8 0 2 , 1 2 9}$ & $\mathbf{9 , 4 3 5 , 4 1 1}$ & $\mathbf{9 , 7 2 9 , 3 5 0}$ & \\
\hline
\end{tabular}

Pengembangan pariwisata perlu dilakukan dalam rangka menarik minat wisatawan. Menurut (Muttaqin, 2011) pengembangan pariwisata dapat mendorong pengembangan beberapa sektor sekaligus, seperti mengubah atau membuat usaha baru yang terkait jasa, perjalanan, memperluas pasar barang-barang lokal, memiliki efek positif pada pekerjaan dan memperlancar peredaran ekonomi dalam perjalanan bisnis daerah tujuan. Istilah ini dikenal dengan multiplier effect. Wisata spiritual akhir-akhir ini menjadi tren baru dalam industri pariwisata. Wisata spiritual sangat menghargai budaya lokal, mencintai alam dan lingkungan, serta wisatawan yang datang juga diajarkan untuk mengenal budaya lokal (Budiastawa, 2009). Wisata jenis ini dapat menjadi potensi di Indonesia, karena melihat Indonesia yang kaya akan budaya.
Candi Parahyangan Agung Jagatkarta terletak di Gunung Salak, Ciapus, Bogor. Candi ini memiliki keindahan alam yang tidak dapat dipungkiri lagi, karena letaknya dibawah kaki Gunung Salak. Tempat ini berpotensi untuk dijadikan suatu objek wisata spiritual, karena Pura Parahyangan ini masih dijadikan tempat beribadah oleh umat Hindu. (Kusumawardhani, 2016)telah membuat suatu model optimasi dalam pengembangan destinasi wisata spiritual di Pura Parahyangan Agung Jagatkartta. Model optimasi yang terbentuk adalah Pemerintah membentuk tim yang bekerja bersama-sama dengan masyarakat sekitar Pura untuk menciptakan sebuah program yang bertujuan meningkatkan akses ke tempattempat wisata seperti penyediaan transportasi publik menuju destinasi wisata, memperbaiki jalan ke objek wisata dan informasi lebih lanjut tentang tempat-tempat wisata dengan membuat 
sebuah website yang berisi tentang Pura Parahyangan Agung Jagatkartta. Model optimasi ini membantu bagi pihak mana saja baik swasta maupun pemerintah dalam mengembangkan destinasi wisata spiritual. Namun, selalu ada risiko di dalam mengembangkan suatu objek wisata. Risiko yang ada perlu dikelola dengan baik agar dapat membantu untuk meminimalkan kerugian dan meningkatkan kesempatan ataupun peluang yang ada. Pengelolaan risiko ini sering disebut dengan manajemen risiko. (Marimin, 2010) Manajemen risiko dapat membantu mengurangi kemungkinan ketidakpastian yang dapat menyebabkan kerusakan atau kerugian. Mengurangi risiko dalan industri pariwisata dilakukan dengan meningkatkan nilai tambah, efisiensi, dan keunggulan komparatif serta melakukan pengembangan destinasi wisata. Risiko dalam industri pariwisata sangat besar seiring dengan meningkatnya pariwisata (Djohanputro, 2008)). Risiko di industri pariwisata dan perhotelan muncul sebagai akibat adanya interaksi manusia.

(Hadiguna, 2010) pada dasarnya ada lima aliran yang dapat dianalisis dalam pariwisata manajemen risiko yaitu risiko operasional, risiko keuangan, risiko informasi, risiko relasional, dan risiko inovasional. Risiko yang sering terjadi dalam industri pariwisata adalah risiko operasional. Risiko operasional dan reputasi di industri pariwisata dan perhotelan dapat berdampak pada risiko lainnya yang relevan (Kountur, 2008)). Risiko operasional dalam pariwisata disebabkan oleh manusia dan alam.

Berdasarkan paparan yang telah disampaikan dalam latar belakang di atas, maka terdapat beberapa pertanyaan penelitian yang dituangkan dalam rumusan masalah ini, adapun rumusan masalahnya adalah:
Bagaimana merumuskan manajemen risiko berbasis ISO 31000 : 2009 pada model optimasi dalam pengembangan destinasi wisata spiritual? Ruang lingkup masalah dalam penelitian ini dibatasi, agar lebih terarah dan mudah dipahami. Penelitian dilakukan di Pura Agung Jagatkartta Ciapus, Bogor. Penelitian ini difokuskan pada perumusan manajemen risiko berbasis ISO 31000:2009 pada model optimasi pengembangan destinasi wisata spiritual khususnya di Pura Parahyangan Agung Jagatkartta.

Adapun tujuan penelitian ini adalah untuk memberikan pamahaman analitis mengenai perumusan manajemen risiko dalam pariwisata. Lebih jauh lagi, penelitian ini bertujuan menemukan risiko-risiko apa saja yang ada pada destinasi wisata spiritual kemudian merumuskan manajemen risiko berbasis ISO 31000:2009 pada model optimasi pengembangan destinasi wisata spiritual. Penelitian ini diharapkan dapat membantu memaksimalkan kinerja model optimasi itu sendiri pada proses implementasinya, yaitu dengan meminimalkan risiko-risiko yang terjadi dengan manajemen risiko berbasis ISO 31000:2009. Kendala atau risiko yang ada dapat ditanggulangi secara cepat dengan cara pemberdayaan masyarakat dan penggunaan teknologi lokal yang tepat guna secara efektif dan efisien.

\section{MATERI DAN METODE}

Penelitian ini menggunakan berbagai teknik untuk mencapai tujuan yang telah ditetapkan. Penilaian risiko pada destinasi wisata spiritual menggunakan manajemen risiko ISO 31000:2009. 
Gambar 1. Proses Manajemen Risiko Berdasarkan ISO 31000:2009

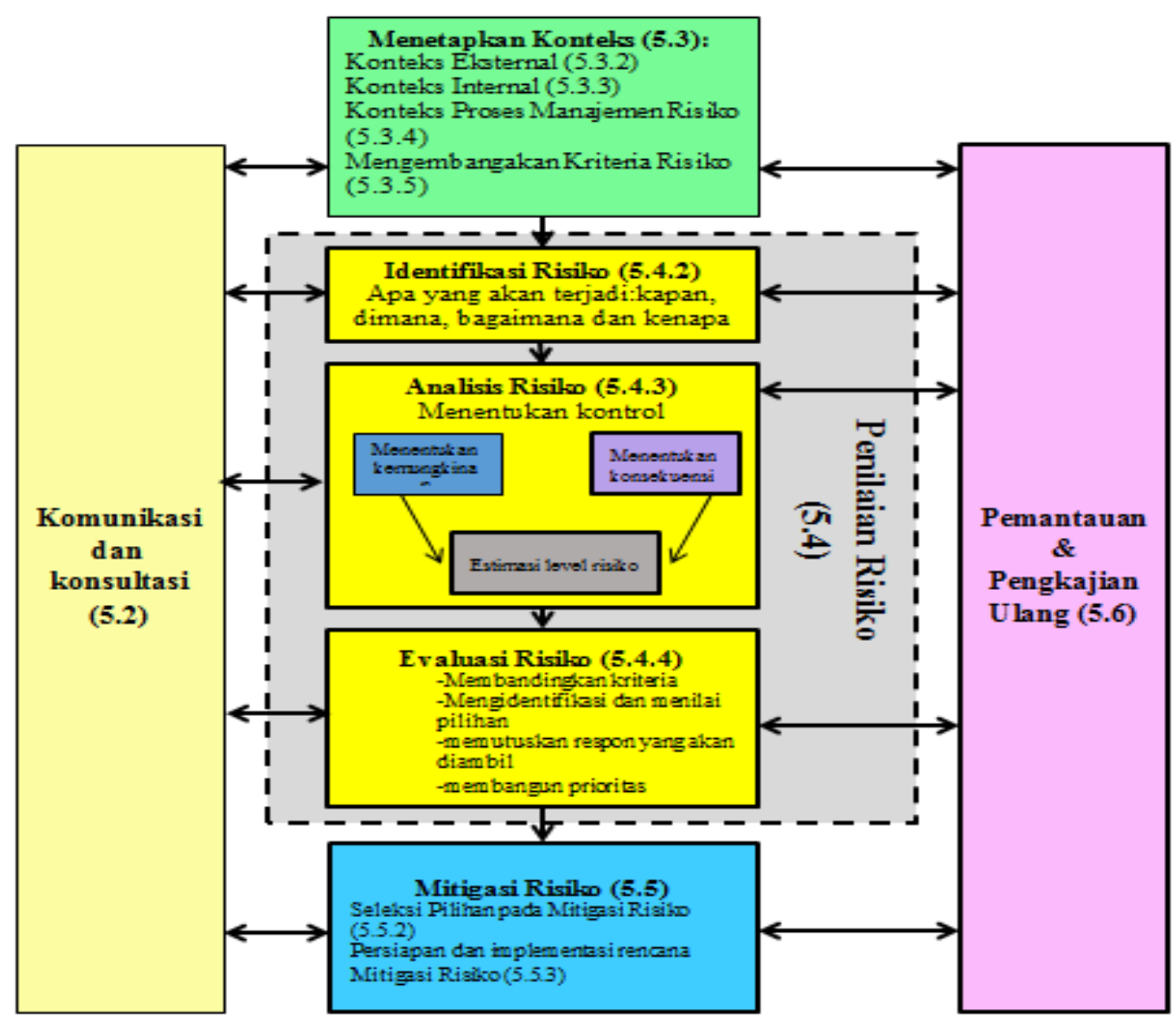

\section{PEMBAHASAN}

Asesmen risiko merupakan bagian yang paling penting dan fundamental dalam proses pengelolaan risiko (Muslich, 2007). Oleh karena itu, organisasi perlu melakukan asesmen risiko yang benar agar memperoleh laporan profil risiko yang tepat sehingga organisasi dapat secara cermat mengelola risikonya. Proses manajemen risiko merupakan kegiatan kritikal dalam manajemen risiko, karena merupakan penerapan dari pada prinsip dan kerangka kerja yang telah dibangun (Siahaan 2007). Proses manajemen risiko terdiri dari tiga proses besar, yaitu: Penetapan konteks (establishing the context); penilaian risiko (risk assessment; penanganan risiko (risk treatment). Ketiga proses besar tersebut didampingi oleh dua proses yaitu: komunikasi dan konsultasi; monitoring dan review.

\section{Penetapan Konteks (establishing the context)}

Penetapan konteks bertujuan untuk mengidentifikasi dan mengungkapkan sasaran organisasi, lingkungan dimana sasaran hendak dicapai, stakeholders yang berkepentingan, dan keberagaman kriteria risiko, dimana hal-hal ini akan membantu mengungkapkan dan menilai sifat dan kompleksitas dari risiko. Terdapat empat konteks yang perlu ditentukan dalam penetapan konteks, yaitu konteks internal, konteks eksternal, konteks manajemen risiko, dan kriteria risiko. Adapun penetapan konteks internal dan konteks eksternal yang dilakukan dalam penelitian ini mengacu pada pedoman ISO 31000:2009 ditunjukkan dalam diagram fishbone pada gambar 2 dan gambar 3 dibawah.

\section{Penentuan Kriteria Risiko}

Kriteria risiko atau Risk Criteria adalah ukuran standar seberapa besar dampak atau konsekuensi yang mungkin akan terjadi dan seberapa besar kemungkinan atau frekeunsi atau likelihood risiko akan terjadi. kriteria risiko 
digambarkan dengan sebuah matrik, dimana pada sisi vertical matrik terdapat tingkat frekuensi seberapa besar risiko itu terjadi yang sering disebut dengan likelihood of risk. Frekuensi/likelihood of risk terdiri dari lima tingkatan kejadian yaitu rare (jarang terjadi), Unlikely (kemungkinan kecil terjadi), possible (kemungkinan sedang terjadi), probable (kemungkinan besar terjadi), dan almost certain (hamper sering terjadi). Kemudian pada sisi horizontal terdapat tingkat keparahan dari risiko, yang dimana juga terdiri dari lima tingkatan keparahan yaitu : insignificant (tidak signifikan berpengaruh), minor (kecil), moderate (sedang), major (besar), catastrophic/ekstreem (parah/ekstrim). Dalam matriks risiko itu juga terdapat empat kriteria risiko yaitu apakah risiko-risiko itu acceptable/dapat diterima, menjadi issue/diwaspadai, atau unacceptable/tidak diterima, serta memprioritaskan mitigasi atau penangannya. Risiko yang terletak di warna merah atau di daerah unacceptable menjadi prioritas untuk dilakukan penanganan atau mitigasinya.

Gambar 2 Diagram Fishbone Konteks Internal

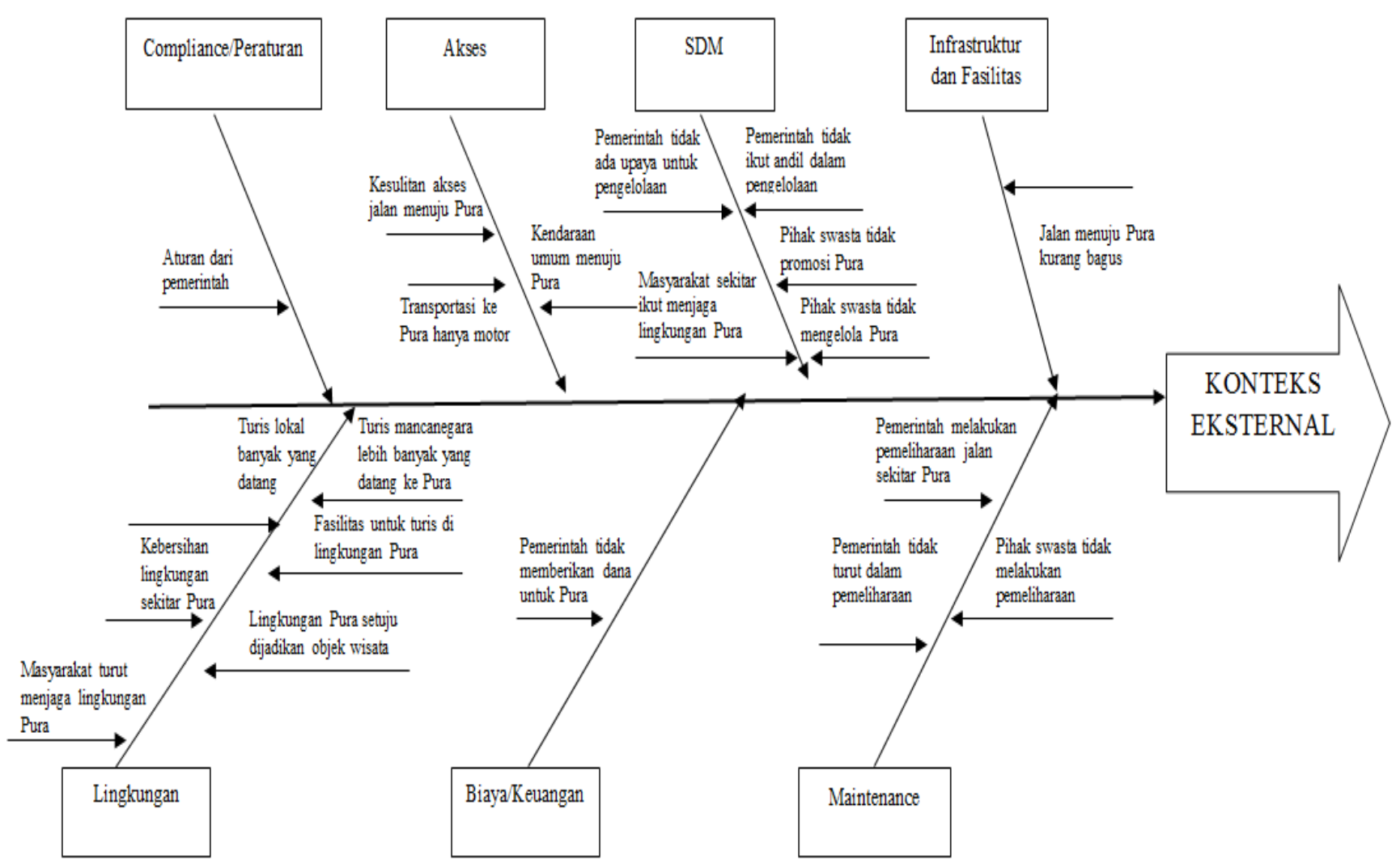


Gambar 3. Diagram Fishbone Konteks Eksternal

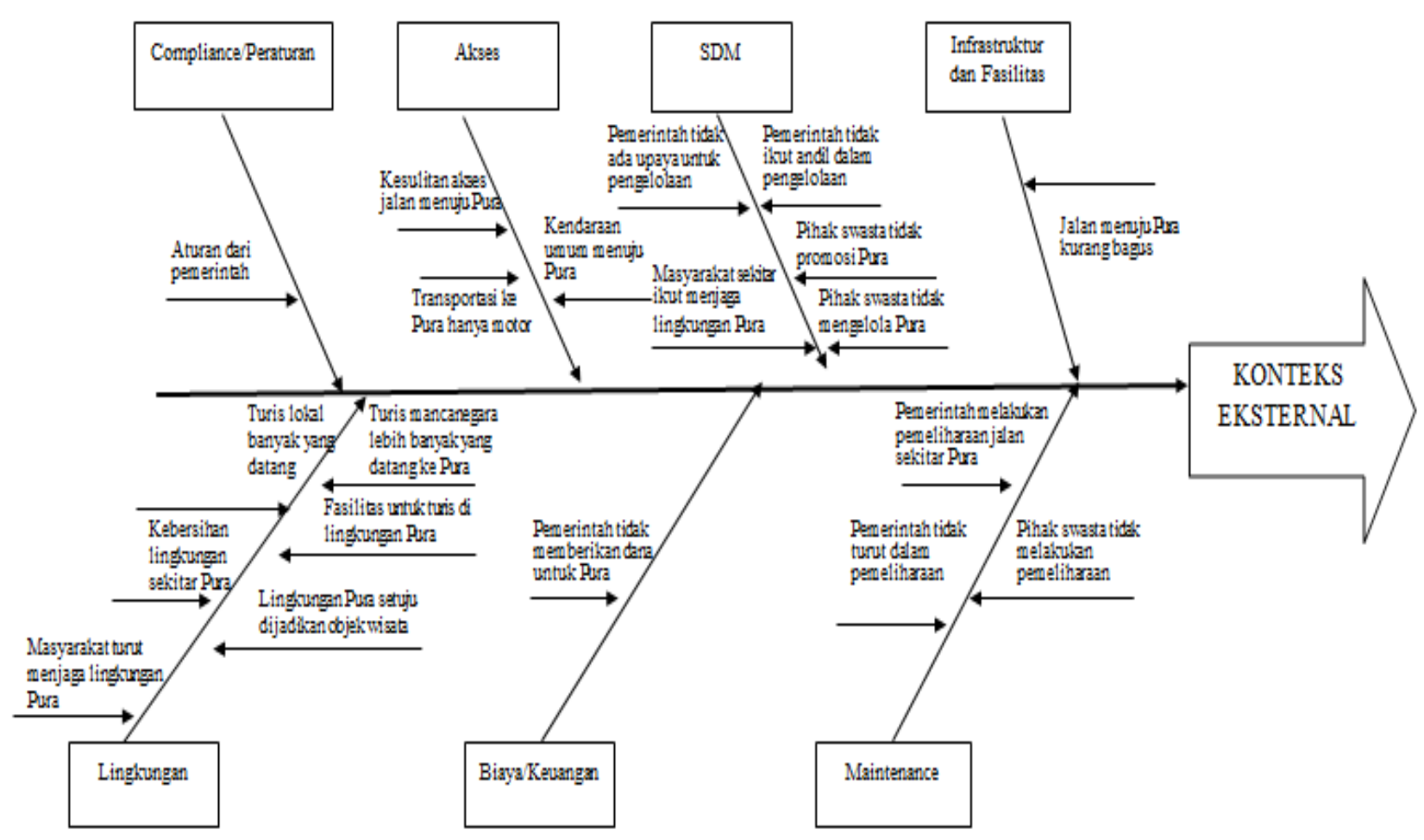

\section{Penilaian Risiko}

Penilaian risiko terdiri dari: Identifikasi risiko: mengidentifikasi risiko apa saja yang dapat mempengaruhi pencapaian sasaran organisasi; analisis risiko: menganalisis kemungkinan dan dampak dari risiko yang telah diidentifikasi; evaluasi risiko: membandingkan hasil analisis risiko dengan kriteria risiko untuk menentukan bagaimana penanganan risiko yang akan diterapkan.

\section{Identifikasi Risiko}

Dalam pelaksanaannya identifikasi risiko merupakan menganalisis risiko-risiko apa saja yang dapat terjadi di masa yang akan datang (apa, kapan, di mana, bagaimana, mengapa suatu risiko bisa terjadi) (Rustam, 2013). Identifikasi ini termasuk pengidentifikasian poses, tugas, aktifitas kritikal atau kunci, pengenalan area-area risiko dan katagorinya. Table 1 menunjukkan risiko apa saja yang terjadi pada model optimasi pengembangan destinasi wisata spiritual di Pura Parahyangan Agung Jagatkarta. 
Table 1 Risiko yang terjadi (Risk Event)

\begin{tabular}{|c|c|c|}
\hline No & Faktor & Risk Event \\
\hline \multirow{8}{*}{1} & \multirow{8}{*}{ Fasilitas/Infrastruktur } & Kamar mandi di Pura kurang memadai \\
\hline & & Pagar-pagar di Pura kurang memadai \\
\hline & & Bale-bale di Pura kurang memadai \\
\hline & & Tempat Pemangku Pura kurang memadai/tidak ada \\
\hline & & Infrastruktur Pura kurang baik \\
\hline & & Jalan di sekitar Pura masing kurang baik \\
\hline & & Sesajen yang disediakan kurang memadai \\
\hline & & $\begin{array}{l}\text { Tulisan Tata tertib memasuki Pura kurang terlihat oleh } \\
\text { pengunjung }\end{array}$ \\
\hline \multirow{5}{*}{2} & \multirow{5}{*}{ Akses } & Akses jalan menuju Pura sulit \\
\hline & & Tidak ada kendaraan umum menuju Pura \\
\hline & & Transportasi yang digunakan menuju Pura hanya motor \\
\hline & & Belum ada informasi khusus mengenai Pura di Internet \\
\hline & & $\begin{array}{l}\text { Banyak turis yang belum mengetahui keberadaan Pura ini } \\
\text { sebagai wisata spiritual }\end{array}$ \\
\hline \multirow{8}{*}{3} & \multirow{8}{*}{ SDM } & Pura memiliki pengelola secara mandiri \\
\hline & & Pengelola Pura bertanggung jawab penuh atas Pura \\
\hline & & $\begin{array}{l}\text { Pengelola Pura sangat berperan untuk terlaksananya kegiatan } \\
\text { di Pura }\end{array}$ \\
\hline & & Pemerintah tidak ikut andil dalam pengelolaan Pura \\
\hline & & Tidak ada upava dari pemerintah untuk pengelolaan Pura \\
\hline & & $\begin{array}{l}\text { Masyarakat sekitar kurang turut menjaga ketertiban, } \\
\text { kenyamanan, dan kebersihan sekitar Pura }\end{array}$ \\
\hline & & $\begin{array}{l}\text { Pihak swasta tidak ada yang turut mempromosikan wisata } \\
\text { spiritual di Pura }\end{array}$ \\
\hline & & Pihak swasta tidak ada yang turut andil dalam mengelola Pura \\
\hline \multirow{8}{*}{4} & \multirow{8}{*}{ Maintenance } & $\begin{array}{l}\text { Pihak pengelola Pura sudah melakukan pemeliharaan Pura } \\
\text { dengan cukup baik }\end{array}$ \\
\hline & & Pengelola Pura sendiri yang melakukan pemeliharaan Pura \\
\hline & & Pemerintah tidak turut serta dalam pemeliharaan Pura \\
\hline & & $\begin{array}{l}\text { Pemerintah hanya melakukan pemeliharaan untuk } \\
\text { infrastruktur jalan sekitar Pura saja }\end{array}$ \\
\hline & & $\begin{array}{l}\text { Pihak swasta tidak ada yang melakukan pemeliharaan pada } \\
\text { Pura }\end{array}$ \\
\hline & & Sistem pemeliharaan yang diterapkan sudah cukup baik \\
\hline & & Tidak ada bagian Pura yang sulit untuk dilakukan pemeliharaan \\
\hline & & Pemeliharaan Pura dilakukan dengan mudah \\
\hline \multirow{8}{*}{5} & \multirow{8}{*}{ Lingkungan } & Turis lokal/mancanegara banyak yang datang \\
\hline & & Lebih banyak turis mancanegara yang datang ke Pura \\
\hline & & Turis tidak boleh masuk ke area dalam Pura \\
\hline & & Turis boleh masuk area dalam Pura apabila ingin meditasi \\
\hline & & Lingkungan sekitar Pura kurang bersih \\
\hline & & $\begin{array}{l}\text { Lingkungan Pura kurang mendukung adanya fasilitas untuk } \\
\text { turis }\end{array}$ \\
\hline & & $\begin{array}{l}\text { Lingkungan sekitar Pura setuju bahwa Pura dijadikan sebagai } \\
\text { tempat pariwisata }\end{array}$ \\
\hline & & $\begin{array}{l}\text { Masyarakat sekitar Pura turut serta dalam menjaga lingkungan } \\
\text { Pura }\end{array}$ \\
\hline
\end{tabular}




\begin{tabular}{|c|c|c|}
\hline \multirow{5}{*}{6} & \multirow{5}{*}{ Keuangan } & Tidak ada sistem retribusi di Pura \\
\hline & & Tidak ada biaya khusus untuk pemeliharaan Pura \\
\hline & & Pemerintah tidak memberikan dana untuk pengelolaan Pura \\
\hline & & $\begin{array}{l}\text { Upacara keagamaan diadakan dengan biaya umat yang berdoa } \\
\text { di Pura }\end{array}$ \\
\hline & & $\begin{array}{l}\text { Dana untuk Pura didapatkan hanya dari sumbangan } \\
\text { perseorangan saja }\end{array}$ \\
\hline \multirow{5}{*}{7} & \multirow{5}{*}{ Peraturan } & Tidak ada peraturan dari pemerintah yang ditetapkan di Pura \\
\hline & & Aturan keagamaan untuk berkunjung ke Pura kurang jelas \\
\hline & & Aturan adat istiadat untuk berkunjung ke Pura kurang jelas \\
\hline & & $\begin{array}{l}\text { Tidak ada sanksi yang tegas dari pengelola Pura untuk turis } \\
\text { yang melanggar aturan berkunjung ke Pura }\end{array}$ \\
\hline & & $\begin{array}{l}\text { Turis tidak mengetahui jadwal-jadwal acara keagamaan yang } \\
\text { dimana Pura di tutup untuk umum }\end{array}$ \\
\hline
\end{tabular}

\section{Analisis Risiko}

Risk Analysis atau analisis risiko-risiko, yaitu proses menentukan berapa besar dampak (impact atau consequences) dan kemungkinan (frequency atau likelihood) risiko-risiko yang akan terjadi, serta menghitung berapa besar level risikonya dengan mengalikan antara besar dampak dan besar kemungkinan (Risk = Consequences $x$ Likelihood).

\section{Risk Evaluation \& Risk Treatment / Mitigasi Risiko}

Mitigasi risiko harus direncanakan dengan baik dengan mempertimbangkan semua alternatifso lusinya. Tabel 2 menunjukkan risiko apa saja yang membutuhkan mitigasi risiko beserta program apa saja yang menjadi mitigasi risiko agar dapat meminimalisir risiko yang terjadi.

Gambar 4. Analisis Resiko

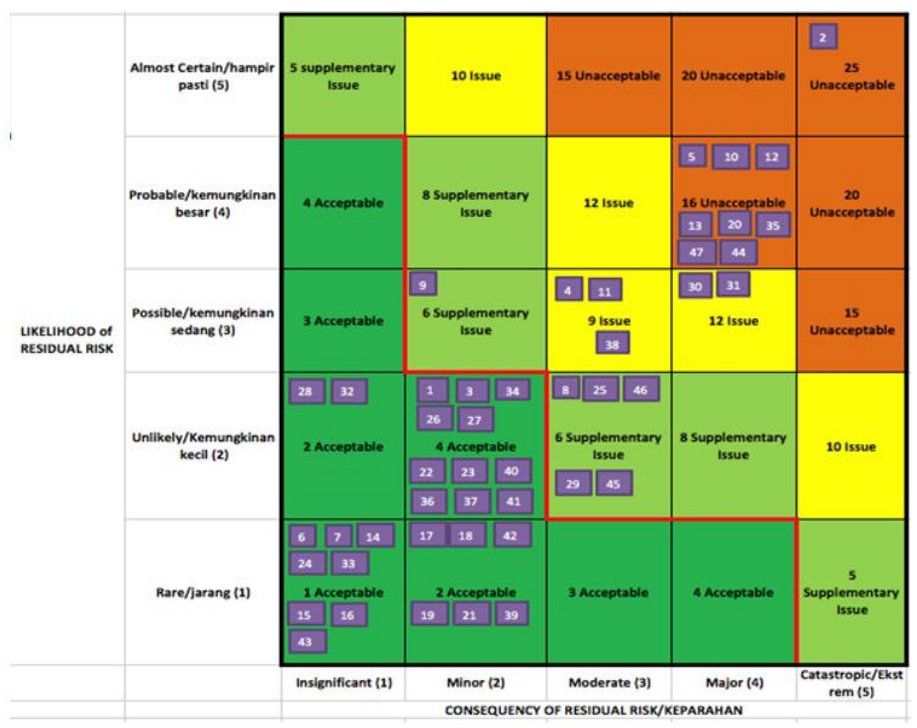


Tabel 2. Risk Mitigation

\begin{tabular}{|c|c|c|c|}
\hline $\begin{array}{c}\text { Tingkat } \\
\text { Risiko }\end{array}$ & \multicolumn{3}{|c|}{ SUPPLEMENTARY ISSUE } \\
\hline No & Faktor & Risk Event & Mitigasi Risiko \\
\hline 8 & $\begin{array}{l}\text { Fasilitas/Infrastrukt } \\
\text { ur }\end{array}$ & $\begin{array}{l}\text { 8. Tulisan Tata tertib memasuki Pura } \\
\text { kurang terlihat oleh pengunjung }\end{array}$ & $\begin{array}{l}\text { Tulisan tata tertib lebih baik diletakkan } \\
\text { di depan gerbang pintu masuk Pura } \\
\text { sehingga pengunjung yang datang } \\
\text { dapat langsung melihat tata tertib } \\
\text { memasuki Pura. }\end{array}$ \\
\hline 45 & Peraturan & $\begin{array}{l}\text { 45. Aturan adat istiadat untuk } \\
\text { berkunjung ke Pura kurang jelas }\end{array}$ & $\begin{array}{l}\text { Dapat dituliskan juga beberapa aturan } \\
\text { adat di papan tata tertib dan diletakkan } \\
\text { di depan pintu gerbang Pura. }\end{array}$ \\
\hline $\begin{array}{l}\text { Tingkat } \\
\text { Risiko }\end{array}$ & \multicolumn{3}{|c|}{ ISSUE } \\
\hline No & Faktor & Risk Event & Mitigasi Risiko \\
\hline 4 & $\begin{array}{l}\text { Fasilitas/Infrastrukt } \\
\text { ur }\end{array}$ & $\begin{array}{l}\text { 4. Tempat Pemangku Pura kurang } \\
\text { memadai/tidak ada }\end{array}$ & $\begin{array}{l}\text { Perlu adanya tempat Pemangku Pura } \\
\text { untuk beristirahat, mengadakan } \\
\text { rapat/meeting, dan sebagai tempat } \\
\text { menunggu }\end{array}$ \\
\hline 11 & Akses & $\begin{array}{l}\text { 11. Transportasi yang digunakan } \\
\text { menuju Pura hanya motor }\end{array}$ & $\begin{array}{l}\text { Saat ini sebenarnya sudah tersedia } \\
\text { angkutan kota yang melewati rute } \\
\text { menuju Pura, hanya saja jumlahnya } \\
\text { yanng masih sedikit, mungkin perlu } \\
\text { ditambah lagi dalam segi jumlah } \\
\text { sehingga wisatawan dapat mengakses } \\
\text { angkutan kota dengan mudah karena } \\
\text { tersedia dalam jumlah yang banyak. }\end{array}$ \\
\hline 30 & \multirow[t]{2}{*}{ Lingkungan } & $\begin{array}{l}\text { 30. Turis lokal/mancanegara banyak } \\
\text { yang datang }\end{array}$ & $\begin{array}{l}\text { Pada kenyataannya hingga saat ini baik } \\
\text { turis lokal maupun mancanegara masih } \\
\text { sangat minim yang datang ke Pura. Hal } \\
\text { ini dikarenakan kurang adanya } \\
\text { promosi dan eksistensi Pura ini pun di } \\
\text { dunia pariwisata di Indonesia masih } \\
\text { sangat kurang. Perlu adanya promosi } \\
\text { dan informasi mengenai keberadaan } \\
\text { Pura ini baik di internet maupun di } \\
\text { sosial media, selain itu dari sisi } \\
\text { Pemerintah juga sebaiknya turut } \\
\text { membantu adanya promosi ke } \\
\text { masyarakat tentang keberadaan Pura } \\
\text { ini. }\end{array}$ \\
\hline 31 & & $\begin{array}{l}\text { 31. Lebih banyak turis mancanegara } \\
\text { yang datang ke Pura }\end{array}$ & $\begin{array}{l}\text { Pura perlu promosi secara besar- } \\
\text { besaran, setidaknya agar Pura ini dapat } \\
\text { diketahui secara luas, pihak Pura harus } \\
\text { memiliki komoitmen untuk } \\
\text { menjadikan pura ini sebagai destinasi } \\
\text { wisata spiritual sehingga pengelola } \\
\text { dapat melakukan promosi secara besar- } \\
\text { besaran dan bekerja sama baik dengan } \\
\text { pihak swasta seperti (hotel dan travel) } \\
\text { dan pihak pemerintah untuk turut } \\
\text { mempromosikan Pura ini sebagai } \\
\text { rekomendasi destinasi wisata spiritual. }\end{array}$ \\
\hline
\end{tabular}




\begin{tabular}{|c|c|c|c|}
\hline 38 & Keuangan & $\begin{array}{l}\text { 38. Tidak ada sistem retribusi di } \\
\text { Pura }\end{array}$ & $\begin{array}{l}\text { Sebaiknya diberlakukan sistem } \\
\text { retribusi yang jelas dan tidak terlalu } \\
\text { mahal sehingga dari retribusi inilah } \\
\text { dapat membantu pemeliharaan Pura. }\end{array}$ \\
\hline $\begin{array}{l}\text { Tingkat } \\
\text { Risiko }\end{array}$ & \multicolumn{3}{|c|}{ UNACCEPTABLE } \\
\hline No & Faktor & Risk Event & Mitigasi Risiko \\
\hline 2 & \multirow{2}{*}{$\begin{array}{c}\text { Fasilitas/Infrastrukt } \\
\text { ur }\end{array}$} & $\begin{array}{l}\text { 2. Pagar-pagar di Pura kurang } \\
\text { memadai }\end{array}$ & $\begin{array}{l}\text { Perlu pembangunan pagar pembatas di } \\
\text { setiap pinggir bangunan Pura dan di } \\
\text { depan gerbang Pura, karena posisi Pura } \\
\text { yang berada di ketinggian yang cukup } \\
\text { tinggi dan berada di tepi jurang } \\
\text { sehingga sangat diperlukan pagar yang } \\
\text { kuat dan kokoh untuk membatasi area } \\
\text { tersebut agar aman. }\end{array}$ \\
\hline 5 & & 5. Infrastruktur Pura kurang baik & $\begin{array}{l}\text { Pura perlu pembangunan kembali baik } \\
\text { untuk pemeliharaan dan penambahan } \\
\text { bangunan baru seperti bale tempat } \\
\text { pemangku Pura dan tempat } \\
\text { pertemuan/ruang rapat, tempat } \\
\text { penyelenggaraan upacara keagamaan, } \\
\text { dan bale-bale tempat untuk } \\
\text { pengunjung. }\end{array}$ \\
\hline 10 & \multirow{3}{*}{ Akses } & $\begin{array}{l}\text { 10. Tidak ada kendaraan umum } \\
\text { menuju Pura }\end{array}$ & $\begin{array}{l}\text { Kendaraan umum menuju Pura sudah } \\
\text { ada namu masih sangat minim } \\
\text { jumlahnya, perlu adanya penambahan } \\
\text { jumlah kendaraan umum menuju Pura. }\end{array}$ \\
\hline 12 & & $\begin{array}{l}\text { 12. Belum ada informasi khusus } \\
\text { mengenai Pura di Internet }\end{array}$ & $\begin{array}{l}\text { Perlu adanya promosi secara besar- } \\
\text { besaran sehingga informasi mengenai } \\
\text { Pura sebagai destinasi wisata spiritual } \\
\text { dapat tersedia. Promosi dapat } \\
\text { dilakukan dengan bekerja sama dengan } \\
\text { pihak swasta (travel dan hotel) dan } \\
\text { pemerintah (Dinas Pariwisata Kota } \\
\text { Bogor), selain itu perlu juga membuat } \\
\text { website/sosial media yang berisi } \\
\text { informasi tentang Pura. }\end{array}$ \\
\hline 13 & & $\begin{array}{l}\text { 13. Banyak turis yang belum } \\
\text { mengetahui keberadaan Pura ini } \\
\text { sebagai wisata spiritual }\end{array}$ & $\begin{array}{l}\text { Pihak Pura dapat mengadakan upacara } \\
\text { adat/keagamaan yang dapat menarik } \\
\text { turis (lokal/mancanegara) tanpa } \\
\text { mengganggu berjalannya upacara } \\
\text { adat/keagamaan tersebut. Hal ini dapat } \\
\text { menjadi daya tarik tersendiri bagi } \\
\text { wisatawan sebagai destinasi wisata } \\
\text { spiritual. }\end{array}$ \\
\hline 20 & SDM & $\begin{array}{l}\text { 20. Pihak swasta tidak ada yang } \\
\text { turut mempromosikan wisata } \\
\text { spiritual di Pura }\end{array}$ & $\begin{array}{l}\text { Pihak pengelola Pura perlu bekerja } \\
\text { sama dengan pihak swasta baik itu } \\
\text { hotel atau travel agent untuk turut } \\
\text { mempromosikan Pura sebagai destinasi } \\
\text { wisata spiritual di Kota Bogor. }\end{array}$ \\
\hline
\end{tabular}




\begin{tabular}{|c|c|c|c|}
\hline 35 & Lingkungan & $\begin{array}{l}\text { 35. Lingkungan Pura kurang } \\
\text { mendukung adanya fasilitas untuk } \\
\text { turis }\end{array}$ & $\begin{array}{l}\text { Ketika pihak pengelola Pura } \\
\text { berkomitmen untuk menjadikan pura } \\
\text { sebagai destinasi wisata spiritual } \\
\text { dengan segala upayanya menujuke } \\
\text { arah situ, maka pihak pengelola dapat } \\
\text { menarik para wirausaha untuk } \\
\text { membuka usahanya seperti restaurant } \\
\text { atau hotel di sekitar Pura sehingga } \\
\text { wisatawan yang yang datang ke Pura } \\
\text { tidak perlu bingung mencari tempat } \\
\text { makan atau menginap. Selain itu, } \\
\text { pemandangan yang disediakan di } \\
\text { sekitar Pura pun sangat indah dengan } \\
\text { pemdangan di kaki gunung salak. }\end{array}$ \\
\hline 44 & Peraturan & $\begin{array}{l}\text { 44. Aturan keagamaan untuk } \\
\text { berkunjung ke Pura kurang jelas }\end{array}$ & $\begin{array}{l}\text { Perlu adanya aturan keagamaan secara } \\
\text { tertulis dan jelas yang diletakkan di } \\
\text { tempat yang strategis sehingga setiap } \\
\text { pengunjung yang datang dapat melihat } \\
\text { setiap peraturan yang ditetapkan oleh } \\
\text { pihak Pura, diantaranya seperti cara } \\
\text { berpakaian ketika masuk Pura, tata } \\
\text { tertib ketika berada di Pura, jam } \\
\text { operasional Pura, dan lainnya. }\end{array}$ \\
\hline
\end{tabular}

\section{Komunikasi dan Konsultasi}

Komunikasi dan konsultasi merupakan hal yang penting mengingat prinsip ISO 31000:2009 manajemen risiko yang kesembilan menuntut manajemen risiko yang transparan dan inklusif, dimana manajemen risiko harus dilakukan oleh seluruh bagian organisasi yang dimaksud disini adalah pengelola Pura dan memperhitungkan kepentingan dari seluruh stakeholders Pura. Adanya komunikasi dan konsultasi diharapkan dapat menciptakan dukungan yang memadai pada kegiatan manajemen risiko dan membuat kegiatan manajemen risiko menjadi tepat sasaran.

\section{Monitoring dan Review}

Monitoring dan review diperlukan untuk memastikan bahwa implementasi manajemen risiko telah berjalan sesuai dengan perencanaan yang dilakukan. Hasil monitoring dan review juga dapat digunakan sebagai bahan pertimbangan untuk melakukan perbaikan terhadap proses manajemen risiko. ISO 31000: 2009 Risk Management - Principles and Guidelines merupakan standar yang dibuat untuk memberikan prinsip dan panduan general dalam penerapan manajemen risiko. Standar ini menyediakan prinsip, kerangka kerja, dan proses manajemen risiko. Prinsip manajemen risiko merupakan fondasi dari kerangka kerja dan proses manajemen risiko, sedangkan kerangka kerja manajemen risiko merupakan struktur pembangun proses manajemen risiko. Proses manajemen risiko merupakan penerapan inti dari manajemen risiko, sehingga harus dijalankan secara komprehensif, konsisten, dan terus diperbaiki sesuai dengan keperluan. Implementasi manajemen risiko berbasis ISO 31000: 2009 secara mendetail dan menyeluruh pada ketiga komponen tersebut diharapkan dapat meningkatkan efektivitas manajemen risiko yang terdapat di Pura.

\section{KESIMPULAN}

Kesimpulan sektor parawisata di Indonesia memiliki kontribusi yang besar pada perrkonomian Negara. Pengembangan pariwisata saat ini sedang tren salah satunya adalah wisata spiritual, salah satunya pura Parahyangan Agung Jagatkartta di bawah kaki gunung salak. Pada pengembangan destinasi wisata terdapat risikorisiko yang akan dihadapi pengembang, dalam penelitian ini bertujuan untuk menemukan risiko-risiko, dengan proses implementasi model optimasi kemudian merumuskan manajemen risiko berbasis ISO 31000:2009. Model optimasi ini dapat membantu memaksimalkan kinerja model optimasi itu sendiri pada proses implementasinya, yaitu dengan meminimalkan risiko-risiko yang ada yang terjadi.

\section{DAFTAR PUSTAKA}

[BPS] Badan Pusat Statistik. 2015. Tingkat Pertumbuhan Kedatangan Turis Asing ke Indonesia 2007-2015 [Internet]. [diunduh 20178 April]. Tersedia pada: http://bps.go.id 
[Disbudpar] Dinas Budaya dan Pariwisata Provinsi Jawa Barat. 2015. Pura Parahyangan Agung Jagatkartta Taman Sari Gunung Salak Tahun 2015 [Internet]. [diakses 2016 Mei 10]. Tersedia pada: http//www.disbudpar.jabarprov.go.id

Budiastawa, Putu. 2009. Wisata Eko-Spiritual sebagai alternatif pengembangan Bukit Bangli di Kabupaten Bangli (Tesis Program Magister Pariwisata). Denpasar (ID): Universitas Udayana.

Djohanputro, B. 2008. Manajemen Risiko Korporat Terintegrasi. Jakarta (ID): PPM.

Hadiguna, R. 2010. Perancangan Sistem Penunjang Keputusan Rantai Pasokan dan Penilaian Risiko Mutu Pada Agroindustri Kelapa Sawit Kasar [disertasi]. Bogor (ID): Institut Pertanian Bogor.

ISO 31010. 2009. International Standard: Risk Management-Risk Assessment Technique. Geneva, Switzzerland: IEC (Internation Electrotechnical Commission).

Kountur, R. 2008. Manajemen Risiko Operasional Perusahaan. Jakarta (ID) : PPM.
Kusumawardhani, Yuviani. 2016. Optimization Model Analysis to Develop Destination Travel : The 8th International graduate School and Scholars' Conference in Indonesia, 26-27 Oktober 2016. Universitas Gajah Mada, Yogyakarta.

Marimin, Maghfirof N. 2010. Aplikasi Teknik Pengambilan Keputusan Dalam Manajemen Rantai Pasok. Bogor (ID): IPB Pr.

Muslich, M. 2007. Manajemen Risiko Operasional Teori dan Praktek. Jakarta (ID): PT Bumi Aksara.

Muttaqin, T, Ris Hadi Purwanto, dan Siti Nurul Rifiqo. 2011. Kajian Potensi dan Strategi Pengembangan Ekowisata di Cagar Alam Pulau Sempu Kabupaten Malang Provinsi Jawa Timur. Jurnal GAMMA (6)2: 152-161.

Rustam, Bambang Riyanto. 2013. Manajemen Risiko Perbankan di Indonesia. Jakarta (ID) : Salemba Empat

Siahaan, H. 2007. Manajemen Risiko. Jakarta (ID): PT Elex Media Computindo. 